\title{
Teaching and reform of communication principles based on EDA theory
}

\author{
Hu Bowen \\ School of Electronics and Information Engineering, Jingchu University of Technology, \\ Jingmen 448000,China
}

Keywords: EDA; teaching methods; reform; communication theory

\begin{abstract}
EDA technique is the development of modern electronic design, which must be grasped by modern electronic engineer. A new method of curriculum design which is based on the traditional course design method of communication theory using EDA technology is put forward and practiced so that students can understand the working principle of communication system further. By reform, we improve the teaching effect, stimulate innovation ability of students and improve the practical ability of students.
\end{abstract}

\section{Introduction}

Communication theory course is a professional course of electronic information technology, its basic content is the basic principles, methods and analysis about performance of the communication systems, it is to explain the basic principles and properties of a variety of modulation and encoding, so as to the students can study and design new communication systems, master the development direction and specific technology of communication systems. In order to enable students to further understand the basic principles of various communication systems, further understand the nature of communication systems, fully understand the importance of communication in its field of expertise, the course of communication and electronic information is generally designed after the course of communication principles. The purpose is to grasp the method of the system through the design of a certain type of communication system. And learn how to test their performance and make theory better guide practice.

Because of the limited experiment items and theoretical principles, students can only understand some of the principles of communication systems, besides, they all have a vague understanding of the design of a complete communication system.

EDA is a course which takes advantage of the advanced development platform, uses the hardware description language to design programming's and finally, realizes the application of digital system on programmable gate array. Besides, its remarkable characteristic is the application of advanced technology, software and hardware together and practical engineering.

So, the introduction of EDA technology in the course of communication theory with the advanced design methods and concepts is the main idea in this paper.

\section{EDA applications and its advantages}

EDA in teaching, scientific research, product design and manufacturing and other aspects plays a tremendous role. In teaching, almost all engineering(especially electronic information)class universities are opened EDA courses. Mainly is to let students understand the basic concepts and EDA, and grasp the basic principle in HDL language compose standard, and grasp the logic synthesis theory and algorithm, using EDA tools for electronic circuit of experiment and engaging in the simple system design. General learning circuit simulation tools and PLD development tools, for the future work to lay the foundation.

The EDA mainly does three auxiliary design work: Integrated circuit (IC) design, electronic 
circuit design and printed circuit board (PCB) design, the design document is completed according to schematic diagram or hardware description language HDL on the EDA platform.

Advantages of EDA technology:(1) Hardware description language is used to facilitate complex system design.(2) Powerful system modeling and circuit simulation functions.(3) Having independent intellectual property rights.(4) Standardized development techniques.(5) Making full use of computer automatic design, simulation and test technology.

\section{The necessity of introducing EDA into the course of communication theory}

EDA technology refers to the circuit design, system simulation, PCB layout and manufacturing automation, and fault diagnosis of the electronic design process, it uses the computer simulation as the core of the new electronic circuit design concept, which changes the traditional methods. Meanwhile, it also triggers a revolution in the field of electronic engineering design. This revolution has also accelerated the pace of reform in electronic engineering education. According to the datas, some developed countries have taken EDA as one of the important means of electronic engineering education, and it is necessary to adopt EDA technology to reform traditional electronic engineering teaching.

1.Requirements for the development of communication technology. The software radio technology is a key technology in the future in the field of communication whose important value is that the hardware and software radio equipment is an open, standardized and modular universal hardware platform for wireless communication, and the main communication function is realized by software. However, one of the main digital means is to use CPLD and FPGA as the hardware platform using hardware of EDA technology is a kind of application of EDA in the software defined radio. The development of EDA technology has revolutionized the design method of traditional communication system. The integration of software and hardware design of communication system provides a new means for the design of communication system.

2. A market demand for EDA talents. EDA technology has become the most effective tool for modern electronic system design and electronic product development. It is a basic tool used by electronic engineers. The market has an urgent demand for EDA talents, and those skilled in EDA technology will be welcomed by employers. Therefore, the introduction of EDA technology into the curriculum design of University in the courses of communication and electronic information is the need for training innovative and practical talents.

3.Requirements for the reform of teaching methods. Because the EDA software provides users with a variety of electronic testing instruments and analysis tools, the application of EDA technology in the curriculum design can save design funds, shorten design time, and improve the efficiency and effect of design. Therefore, in order to meet the needs of the development of information technology we should change the

traditional teaching mode and structure, combine the EDA with the curriculum design in communication theory. Besides, It also the inevitable trend of teaching reform in higher education practice.

\section{Reform of teaching content}

1. Textbooks option. Firstly, According to the teaching requirements of EDA, we have looked up many teaching materials at home and abroad, and combined with the development of EDA technology, we have chosen the teaching materials and auxiliary suitable for students majoring in measurement and control.

2. Content of courses option. After several years' teaching, the author believes that we should teach this course as follows: teaching basic concepts, mastering basic skills, taking into account both comprehensiveness and systematicness of content. The course content is summed up as four knowledge points: (1) large scale programmable logic devices (2)hardware description language (3) commonly used EDA soft wares (4)experimental system of EDA. 


\section{Reform of teaching methods}

The principle and application of EDA is offered after the students have completed the course of specialized basic whose specialty is measurement and control. In view of the characteristics of students in this period, and referring to the teaching mode of EDA in other universities at home and abroad, the research group has made many reforms and attempts in teaching methods.

1.Reform of teaching hours. The total hours of the course was 32. In order to enable students to master the course better, we make the total hours of the course to 40 after a fewer years' practicing. We change the traditional teaching mode as the guidance heuristic teaching mode in theoretical teaching. Through this theoretical explanation and experimental teaching, students can grasp the basic knowledge and the basic concept of EDA better. Besides, with this method, the students' sense of participation can be awakened and students will feel the powerful function of EDA.

2. Reform of teaching mode. Multimedia teaching is the mainstream of the reform of teaching methods. We should try our best to use multimedia tools proper to optimize the teaching effect, and find innovative points and breakthroughs for teaching reform. The group designs multimedia courseware. Blackboard writing and multimedia teaching are combined to make full use of the network resources provided by the school. So as to improve the students' learning efficiency, and lay a solid foundation for the students to follow the specialized courses.

3.Reform of teaching methods. The teaching methods of heuristic, questioning,

discussion are used in the course of EDA principles and applications. Research background is also often introduced. Leading the students to explore and ponder and in order to broaden the students' thinking, we should introduce the practical issues timely.

In order to inspire students to think, arouse the students' desire for knowledge, make them study active, we should prepare question carefully under the reference of teaching content.

\section{Reform of practical teaching}

Practical teaching is an indispensable link in theoretical teaching. In order to improve the students' ability to apply what they have learned and the quality of the project, the research team draws advanced ideas of experimental teaching. They combine the theory teaching with the experiment teaching and reform the experimental teaching step by step. According to the characteristics of EDA technology, the practical teaching is divided into two parts: basic experimental teaching and curriculum design

1. Basic practical teaching. The reform of experiment teaching content decides the success of experiment teaching reform to a great extent. Most of the previous experimental teaching contents are the experimental verification, that is, students conduct experiments according to the steps in the overall outline of the experiment and in this process, students do more work, but don not think enough. This verification experiment has a single nature.

At present, we have adjusted the experiment contents from confirmatory to comprehensiveness, validation and design. In the course of teaching, it also permeates the experiment, and the students can design EDA in the Intelligent Instrument Laboratory of the Electric Institute. For some good students,

After finishing the necessary experiments, they can also carry out some comprehensive experiments.

2. Curriculum design. In order to enable students to better grasp the relevant EDA technology, improve their innovative ability, and cultivate their innovative thinking,the research term opens a course design for Senior students which will last three weeks. In the integrated curriculum design, students can search for the resources and draw up the plan under the help of teachers until the subject is completed.

By finishing the integrated curriculum design, the students' ability to apply the theoretical knowledge in a comprehensive way is nurtured. Besides, their ability to analyze and solve problems is strengthened, and their manipulative ability is also improved. 


\section{Concluding remarks}

EDA technique is the development tendency of modern electronic design, which must be grasped by modern electronic engineer. This article studies the characteristics of "EDA Theory and Application", which explores and practices the teaching reform of "EDA Theory and Application" from the teaching contents, teaching methods and practice teaching. By reform, we improve the teaching effect, stimulate innovation ability of students and improve the practical ability of students.

However, with the continuous enrichment and perfection of EDA technology, a variety of new technologies, new processes and new products are emerging. Therefore, how to improve the teaching content of EDA courses, how to improve the students' practical application of EDA technology, and how to stimulate students' innovative ability are still need further exploration and practice.

\section{References}

[1]Wang Jian. Research on the introduction of EDA technology into the teaching of electronic courses[J]. Journal of University of Electronic Science and technology of China, 2002,( 2). 91-94.

[2]Pan Song, Huang Jiye. Practical tutorial of EDA technology[M].Beijing: The Science Publishing Company.2005:4-5.

[3]Wang Ping. Practice of teaching method of EDA course[J]. Mechanical manufacturing and research.2010,39(2):99-100.

[4]Guo Yanqing. Application of EDA in basic experiment teaching[J]. Journal of electrical and electronic teaching.2010,(32):215-221.

[5]Huang Weihua. Review of experimental system development of EDA[J]. value engineering.2010:146-147. 